\title{
A comparison of antibiotic-sterilized, stent-mounted pulmonary and aortic valve allografts in the mitral region of dogs
}

\author{
J. L. MON R O, J.B. G A V I N, \\ and B. G. BARRATT-BOYES ${ }^{1}$ \\ Cardiothoracic Surgical Unit, Green Lane Hospital, 'A uckland, New Zealand
}

\begin{abstract}
Monro, J. L., Gavin, J. B., and Barratt-Boyes, B. G. (1974). Thorax, 29, 323-328. A comparison of antibiotic-sterilized, stent-mounted pulmonary and aortic valve allografts in the mitral region of dogs. The mitral valves of 40 dogs were replaced with antibioticsterilized, stent-mounted semilunar valve allografts. Twenty grafts were pulmonary valves and 20 were aortic valves. Six dogs in each group died from causes related to the operation. All remaining dogs with pulmonary valve grafts died of causes related to the allograft itself (vegetative endocarditis (5), peripheral leak (1), cusp rupture (4), cusp shrinkage (4)). In the aortic valve group there were seven deaths from allograft endocarditis and one from a peripheral leak, but six dogs had competent allografts when sacrificed up to 12 months after surgery. It is concluded that the inherent strength and bulk of the aortic valve cusps make this valve a more suitable mitral valve replacement than the more delicate pulmonary valves.
\end{abstract}

As an alternative to prosthetic valves with their thromboembolic problems, aortic allograft valves have been used with success in large numbers in the aortic region (McDonald et al., 1968; BarrattBoyes, 1971; Yacoub, Knight, Towers, and Somerville 1973; Layton et al., 1973) and to a lesser extent in the mitral region (Graham, Schroeder, Daily, and Harrison, 1971; Lennox et al., 1971; Barratt-Boyes et al., 1972; Angell, Wuerflein, Chun, and Shumway, 1973). The behaviour of the aortic valve when used as a mitral valve replacement has also been fairly extensively investigated in animals (Howard, Willman, and Hanlon, 1960; Heimbecker et al., 1962; McKenzie et al., 1966; Suzuki and Kay, 1966; Angell, Wuerflein, and Shumway, 1967; Hubka, Siska, and Holec, 1967; Weldon, Ameli, and Morovati, 1967; Braunwald, Fuchs, and Bonchek, 1968; Sugie et al., 1969).

When used in the mitral position the semilunar valve should be at least $24 \mathrm{~mm}$ in internal diameter, for with small valves pressure gradients are present in adult patients (Barratt-Boyes et al., 1972). While aortic allografts of greater diameter

'Supported by a grant from the Medical Research Council of New Zealand than this are unusual, particularly from young donors, larger diameter pulmonary valves are common, and this valve is virtually always free from disease. Accordingly, it was decided to assess the behaviour of the pulmonary valve in the mitral position in dogs. The only previous comparable experimental studies are those of Lower, Stofer, and Shumway (1960), who used first the autologous pulmonary valve and later the untreated pulmonary valve allograft (Lower and Shumway, 1963) to replace the mitral valve. These studies indicated good graft function over a twoyear period.

This paper describes a study which compares pulmonary valve allografts with aortic valve allografts used to replace the mitral valve in dogs.

\section{MATERIALS AND METHODS}

Aortic and pulmonary valves were dissected under sterile conditions from the hearts of donor dogs and stored in Hanks's balanced salt solution containing, per millilitre, 50 units penicillin, $1 \mathrm{mg}$ streptomycin, $1 \mathrm{mg}$ kanamycin, and 25 units amphotericin B. Before insertion the valve allograft was trimmed and mounted under sterile conditions onto a stent constructed 




FIG. 1. A canine pulmonary valve sutured onto the stent ready for insertion. The stent is constructed of stainless steel wire covered with Dacron cloth.

of stainless steel wire covered with Dacron cloth (Fig. 1). In each case the valve was tested for competence under pressure (Barratt-Boyes et al., 1972). The valves were kept in the antibiotic solution for eight to 255 days before use and all were proven to be sterile at insertion.

The 40 dogs used varied between 15 and $35 \mathrm{~kg}$ in weight. Each was anaesthetized with sodium methohexitone and ventilated with halothane, nitrous oxide, and oxygen. Thoracotomy was performed through the right fifth space and cardiopulmonary bypass instituted using a blood and Ringer's lactate prime and a disposable bubble oxygenator. Left atriotomy was performed and the mitral valve excised. The new valve was inserted with about 24 interrupted non-absorbable sutures and the atriotomy was closed.

Postoperatively all dogs were given twice daily penicillin, 1 mega unit, and streptomycin, $0.5 \mathrm{~g}$, for eight days, or longer if indicated. Heparin (5,000 units twice daily) was given intramuscularly for seven days starting the morning after operation. The dogs were kept quiet for the first postoperative month but were then sent to kennels where they were very active. Auscultation was performed at regular intervals and 10 dogs underwent angiography.

Necropsy was performed on all dogs and the heart was removed for examination. Note was made of any blood in the chest, pleural effusions, the state of the lungs, and any abnormal finding. The valve was photographed and placed in phosphate-buffered $5 \%$ glutaraldehyde solution at $\mathrm{pH} 7 \cdot 4$. Seven-micron, paraffinembedded serial sections of each valve cusp were stained with haematoxylin and eosin, van Gieson's stain collagen, Weigert's stain for elastin, phosphotungstic acid haematoxylin for fibrin, and Gram's stain for bacteria.

\section{RESULTS}

Twenty animals received a pulmonary valve allograft and 20 received an aortic valve allograft. In each group there were six deaths at operation or within the first two postoperative days, most commonly from postoperative bleeding.

The outcome in the group receiving pulmonary valves is shown in Table $I$. Of the 14 operative survivors, five animals developed a vegetative endocarditis, four in the first three weeks and one later. In four of these cases bacteria were

T A B L E I

DOGS RECEIVING PULMONARY VALVES

\begin{tabular}{|c|c|}
\hline Cause of Death & No. \\
\hline $\begin{array}{l}\text { Operative death } \\
\text { Vegetative endocarditis } \\
\text { Large peripheral leak } \\
\text { Cusp rupture } \\
\text { Cusp shrinkage }\end{array}$ & $\begin{array}{l}6 \\
5 \\
1 \\
4 \\
4\end{array}$ \\
\hline Total & 20 \\
\hline
\end{tabular}

identified in the blood or in histological sections $\vec{\varphi}$ but in one they were not. Early in the series, one dog was exercised on the seventh postoperative day and died next day from a large perivalvular leak. The remaining eight dogs were well initially but all died from valve failure. Four developed a cusp rupture (Fig. 2 ) with sudden central incompetence and survived an average of 68 days. The $\overrightarrow{\overrightarrow{0}}$ other four developed thinning and shrinkage of $\frac{3}{3}$ the cusps (Fig. 3), which caused progressive central regurgitation, and survived an average of 258 days.

In the group receiving aortic valves (Table II) there were also 14 operative survivors, of which seven developed a vegetative endocarditis, two $\frac{0}{3}$ early and five late. In four of these a bacterial

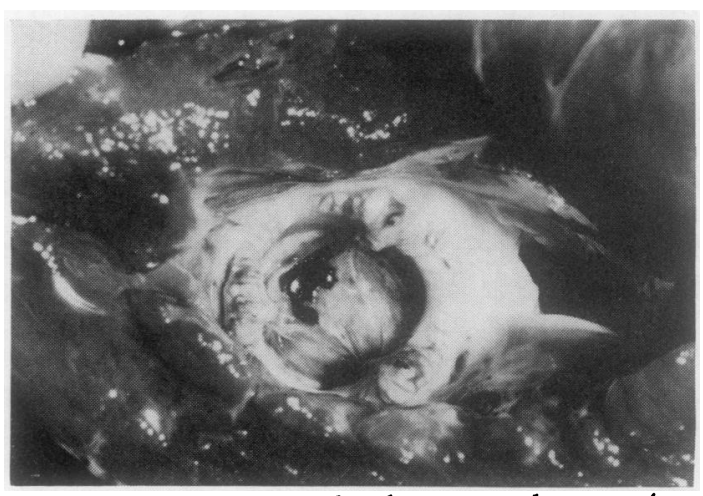

FIG. 2. A stent-mounted pulmonary valve seen from $\stackrel{\Phi}{\varrho}$ the ventricular side from a dog that survived $61 \stackrel{\AA}{\Omega}$ days. One cusp ruptured, causing gross centralo regurgitation.

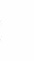

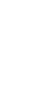

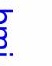

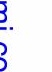

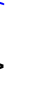




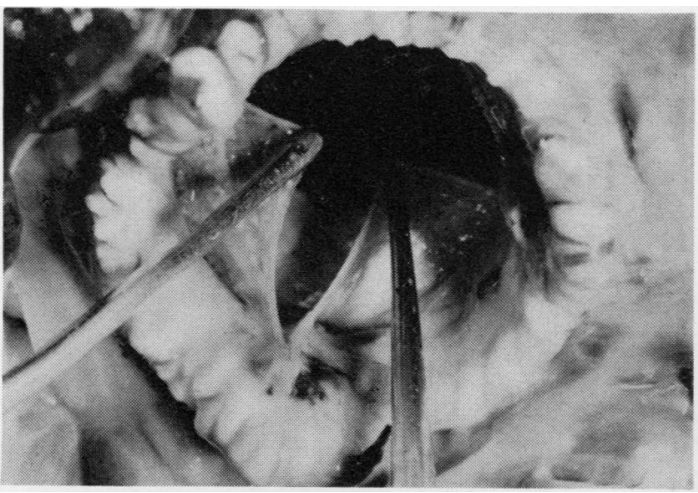

FIG. 3. The cusps of this pulmonary valve (held open with probes) have become extremely thin and shrunken. The dog survived 135 days and died from severe central regurgitation.

T A B L E I I

DOGS RECEIVING AORTIC VALVES

\begin{tabular}{l|c}
\hline Cause of Death & No. \\
\hline Operative death & 6 \\
Vegetative endocarditis & 7 \\
Large peripheral leak & 1 \\
Sacrificed when well & 20 \\
\hline Total & \\
\hline
\end{tabular}

aetiology was confirmed histologically or by blood cultures. One animal died at 33 days due to a large peripheral leak. The other six animals remained clinically well without mitral regurgitant murmurs and each had an angiogram shortly before sacrifice which confirmed valvular competence (Fig. 4). These six valves were examined at intervals ranging from three to 12 months (Table III). In each case the valves were competent with well aligned cusps (Fig. 5) which were very slightly thinner than normal, but this feature did not vary noticeably between those in position for three months and those in position for one year. In no case had the valve pulled away from the stent and all valves were well accepted into the atrium. Behaviour was not related to the duration of storage before use (see Table III).

Histologically the pulmonary valve showed a host response along the interface between the arterial sleeve of the graft and the host tissue which had proliferated through the stent. This was characterized by the presence of lymphocytes and macrophages and a slow replacement of parts of the arterial wall by host connective tissue. Host tissue also proliferated over the intimal surface of the graft from its margin toward, and sometimes onto, the cusps (Fig. 6). The endothelial cells and

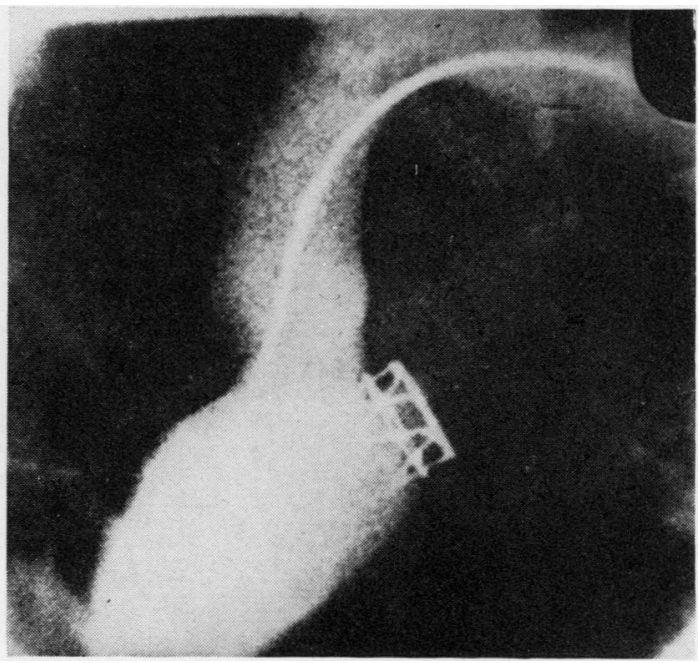

FIG. 4. A left ventricular angiogram showing the metal stent seated in the mitral ring. There is no mitral incompetence and the aorta is seen filling with contrast.

\section{T A B L E I I I}

TIME BEFORE SACRIFICE OF SIX SURVIVING DOGS RECEIVING AORTIC ALLOGRAFTS AND DURATION OF STORAGE OF ALLOGRAFTS IN ANTIBIOTIC SOLUTION

\begin{tabular}{c|c|c}
\multicolumn{2}{|c}{ BEFORE INSERTION } \\
\hline Dog No. & $\begin{array}{c}\text { Survival } \\
\text { (days) }\end{array}$ & $\begin{array}{c}\text { Duration of Storage } \\
\text { (days) }\end{array}$ \\
\hline 21 & 367 & 8 \\
22 & 367 & 102 \\
28 & 269 & 205 \\
36 & 143 & 45 \\
37 & 129 & 22 \\
40 & 94 & 8 \\
\hline
\end{tabular}



FIG. 5. A structurally intact aortic valve removed for examination at 129 days and shown by angiogram to be competent. 


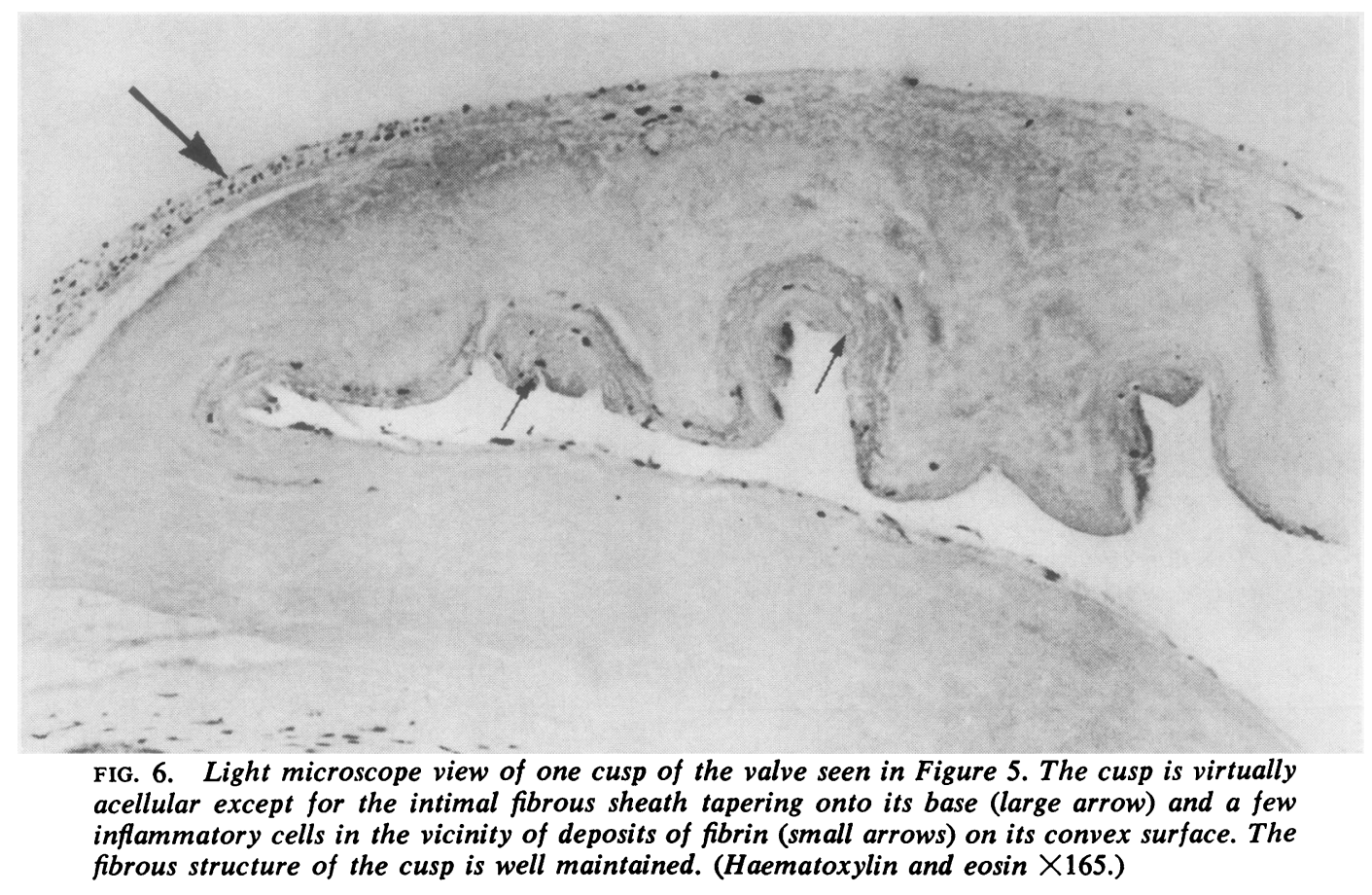

fibroblasts of the graft disappeared, leaving the graft tissue virtually acellular (Fig. 6) apart from the scattered focal infiltrates of fibrin, inflammatory cells, and macrophages. These macrophages appeared to ingest both the intracuspal fibrin and the fibrous matrix of the cusp. They were most numerous in the vicinity of cusp rupture. The collagen and elastin fibres of the graft valves were well preserved except for some disruption in the vicinity of the cellular infiltrates. The aortic valves had inherently more robust cusps but in all other respects were histologically similar to the pulmonary valves. These histological findings are described and discussed in greater detail elsewhere (Gavin and Monro, 1974).

\section{DISCUSSION}

This study has clearly shown that the antibiotictreated dog pulmonary valve allograft, although initially competent, invariably failed when placed in the mitral position. This is in marked contrast to the aortic valve allografts which, apart from those which developed vegetations, functioned well up to one year after insertion.

Allograft failure was due to incompetence, but the mechanism varied between endocarditis, cusp rupture, and cusp shrinkage. The high incidence of endocarditis observed in this study is similar $\overrightarrow{\vec{O}}$ to that reported by other workers in this field 3 (Berghuis et al., 1964; McKenzie et al., 1966; Weldon et al., 1967; Buch, Kosek, Angell, and Shumway, 1971) and is presumably due to the bacteraemias which frequently occur in dogs (Nelson and Noyes, 1954; Das and Rush, 1965). Fortunately, endocarditis is a rare complication 3 in man (Clarkson and Barratt-Boyes, 1970).

Cusp rupture has been the main cause of late $\frac{}{3}$ allograft incompetence in man and on histological study the mechanism seems to be similar in dogs? to that demonstrated in humans (Gavin, Herdson, and Barratt-Boyes, 1972). Cusp shrinkage, on the other hand, had not been recognized as a cause of of late incompetence in man either with pulmon- N ary or aortic allografts and its exact cause in theN dog is uncertain. In transferring these experimental results to man considerable caution is therefore required. It does, however, seem likely from $\stackrel{0}{\circ}$ follow-up of our patients receiving antibiotic- $\stackrel{\infty}{\rightarrow}$ treated pulmonary valve allografts for mitral valve disease that late cusp rupture is relatively commono (Barratt-Boyes et al., 1972) and that, as suggested $\overparen{Q}$ by the present experimental study, this valve is therefore unsatisfactory in the high-pressure mitral position. 
The method of allograft valve preparation is now recognized as vitally important. In the present experimental study the same antibiotic solution as that in use clinically since 1968 (Barratt-Boyes, 1971) has been employed. With this method, tissue culture (Girinath, Gavin, Strickett, and Barratt-Boyes, 1974) and electron microscopic studies (Gavin, Monro, Wall, and Chalcroft, 1973c) indicate that the fibroblasts are structurally damaged and following even short periods of contact with the antibiotics they do not survive implantation in the host for longer than a few weeks (Gavin, Herdson, Monro, and BarrattBoyes, 1973b). Persistent normal function of the leaflet is thus dependent primarily on the integrity of the fibrous tissue. On a longer term basis the growth of a host intimal fibrous sheath onto and into the leaflet will give further support. As in this study, which extended to 12 months only, the intimal fibrous sheaths had rarely grown as far as the cusps, we conclude that it was the inherent strength and bulk of the aortic cusp which enabled them to withstand both the haemodynamic load and the focal depredations of macrophages better than the more delicate pulmonary cusps.

Other workers have suggested that permanent survival and proliferation of the transplanted fibroblasts in the leaflet is necessary for satisfactory long-term function and that this can be achieved only by avoiding antibiotics completely (untreated or 'fresh' grafts) or using lower antibiotic concentrations for shorter periods of time (Angell et al., 1967, 1973). Our detailed histological studies of antibiotic-treated, untreated, and chemically treated grafts in humans convince us that the good long-term function of antibiotic and untreated allografts is related to the integrity of the ground substance of the leaflet and ultimate leaflet replacement by proliferating host fibroblasts (Gavin et al., 1972, 1973a, 1973b).

\section{REFERENCES}

Angell, W. W., Wuerflein, R. D., Chun, C. W., and Shumway, N. E. (1973). Antibiotic sterilisation of aortic homografts. New Zealand Medical Journal, 77, 31 .

,-- , and Shumway, N. E. (1967). Mitral valve replacement with fresh aortic homograft. Experimental results and clinical application. Surgery, $62,807$.

Barratt-Boyes, B. G. (1971). Long-term follow-up of aortic valvar grafts. British Heart Journal, Supplement VI, World Congress, 33, 60.
- , Roche, A. H. G., Agnew, T. M., Cole, D. S., Kerr, A. R., Monro, J. L., Lowe, J. B., and Brandt, P. W. T. (1972). Homograft valves. Medical Journal of Australia, 2, Supplement, 12 August, 38.

Berghuis, J., Rastelli, G. C., van Vliet, P. D., Titus, J. L., Swan, H. J. C., and Ellis, F. H. (1964). Homotransplantation of the canine mitral valve. Circulation, Supplement, 29, p. 47.

Braunwald, N. S., Fuchs, J. C. A., and Bonchek, L. I. (1968). Simplified insertion of aortic homograft valves with nonthrombogenic prosthetic frames. Surgery, 63, 38.

Buch, W. S., Kosek, J. C., Angell, W. W., and Shumway, N. E. (1971). The role of rejection and mechanical trauma on valve graft viability. Journal of Thoracic and Cardiovascular Surgery, 62, 696.

Clarkson, P. M. and Barratt-Boyes, B. G. (1970). Bacterial endocarditis following homograft replacement of the aortic valve. Circulation, 42, 987.

Das, S. K. and Rush, B. F. (1965). Normal bacterial flora in dog blood. Surgical Forum, 16, 74.

Gavin, J. B., Barratt-Boyes, B. G., Hitchcock, G. C., and Herdson, P. B. (1973a). The histopathology of 'fresh' human aortic valve allografts. Thorax, 28, 482.

- Herdson, P. B., and Barratt-Boyes, B. G. (1972). The pathology of chemically-sterilized human heart valve allografts. Pathology, 4, 175.

$\longrightarrow,-$, Monro, J. L., and Barratt-Boyes, B. G. (1973b). The pathology of antibiotic-treated human heart valve allografts. Thorax, 28, 473.

and Monro, J. L. (1974). The pathology of pulmonary and aortic valve allografts used as mitral valve replacements in dogs. Pathology, (In press.)

, Wall, F. M., and Chalcroft, S. C. W. (1973c). Fine structural changes in the fibroblasts of canine heart valves prepared for grafting. Thorax, 28, 748.

Girinath, M. R., Gavin, J. B., Strickett, M. G., and Barratt-Boyes, B. G. (1974). Effects of antibiotics and storage on the viability and ultrastructure of fibroblasts in canine heart valves prepared for grafting. A ustralian and New Zealand Journal of Surgery, (In press.)

Graham, A. F., Schroeder, J. S., Daily, P. O., and Harrison, D. C. (1971). Clinical and hemodynamic studies in patients with homograft mitral valve replacement. Circulation, 44, 334.

Heimbecker, R. O., Baird, R. J., Lajos, T. Z., Varga, A. T., and Greenwood W. F. (1962). Homograft replacement of the human mitral valve. Canadian Medical Association Journal, 86, 805.

Howard, H. S., Willman, V. L., and Hanlon, C. R. (1960). Mitral valve replacement. Surgical Forum, 11, 256.

Hubka, M., Siska, K., and Holec, V. (1967). Replacement of the mitral valve with an aortic valve homograft implanted into the left atrium. Journal of Thoracic and Cardiovascular Surgery, 53, 260. 
Layton, C., Monro, J. L., Brigden, W., McDonald, A., McDonald, L., and Weaver, E. J. M. (1973). Systemic arterial pressure after homograft aortic valve replacement. Lancet, 2, 1343.

Lennox, S. C., Blesovsky, A., Chang, V. P., Cleland, W. P., Ghadiali, P. E., and Aparicio, S. G. R. (1971). Frame-mounted homografts for mitral valve replacement. Journal of Thoracic and Cardiovascular Surgery, 62, 337.

Lower, R. R. and Shumway, N. E. (1963). Replacement of the dog mitral valve with a homograft. Surgical Forum, 14, 247.

Stofer, R. C., and Shumway, N. E. (1960). Autotransplantation of the pulmonic valve into the aorta. Journal of Thoracic and Cardiovascular Surgery, 39, 680.

McDonald, A., McDonald, L., Resnekov, L., Robinson, M., and Ross, D. N. (1968). Homograft replacement of the aortic valve. Lancet, 2, 469.

McKenzie, M. B., Titus, J. L., Rastelli, G. C., Pappas, G., and Ellis, F. H. (1966). Replacement of the canine mitral valve with semilunar valves. Journal of Thoracic and Cardiovascular Surgery, 51, 168.

Nelson, R. M. and Noyes, H. E. (1954). Blood culture studies in normal dogs and in dogs in hemorrhagic shock. Surgery, 35, 782.
Sugie, S., Watanabe, M., Aoki, T., Murakami, T., $\overrightarrow{\overrightarrow{\vec{\omega}}}$ Tanabe, T., Takagi, M., Kubo, Y., Ohta, S., Misaka, K., Tomiyama, M., and Sugiyama, M. 므 (1969). Clinical experience with supported homo- $\frac{\sigma}{\bar{C}}$ graft heart valve for mitral and aortic valve $\bar{s}$ replacement. Journal of Thoracic and Cardio- $\vec{\triangleright}$ vascular Surgery, 57, 455.

Suzuki, A. and Kay, E. B. (1966). A new technique of mitral valve replacement with a homologous $\overrightarrow{0}$ aortic valve. Japanese Circulation Journal, 30, 1193.

Weldon, C. S., Ameli, M. M., and Morovati, S. S. (1967). Mitral and tricuspid valve replacement with stented aortic valve homografts. Archives of Surgery, 95, 862.

Yacoub, M. H., Knight, E., Towers, M., and Somerville, W. (1973). Aortic valve replacement N using fresh unstented homografts. British Heart Journal, 35, 555.

Requests for reprints to: J. L. Monro, F.R.C.S., Wessex Cardiac and Thoracic Centre, Southampton Western Hospital, Oakley Road, Southampton, SO9 4WQ. 